\title{
Assessment of ESAK and ED for Adult's Patients Examined by Computed Radiography
}

\author{
Suhaib Alameen"1, Fatima A. A. Badrey², Abdulrahman S. Abdullateef ${ }^{1}$, Abdelfatah M. Ahmed ${ }^{3}$ \\ ${ }^{1}$ College of Medical Radiologic Science, Sudan University of Science and Technology, Khartoum, Sudan \\ ${ }^{2}$ Sudan Academy of Sciences, Khartoum, Sudan \\ ${ }^{3}$ Department of Medical Physics, Faculty of Science and Technology, Al Neelain University, Khartoum, Sudan \\ Email: Suhaib.sd@hotmail.com
}

How to cite this paper: Alameen, S., Badrey, F.A.A., Abdullateef, A.S. and Ahmed, A.M. (2016) Assessment of ESAK and ED for Adult's Patients Examined by Computed Radiography. International Journal of Medical Physics, Clinical Engineering and Radiation Oncology, 5, 281-287.

http://dx.doi.org/10.4236/ijmpcero.2016.54028

Received: August 10, 2016

Accepted: November 8, 2016

Published: November 11, 2016

Copyright $\odot 2016$ by authors and Scientific Research Publishing Inc. This work is licensed under the Creative Commons Attribution International License (CC BY 4.0).

http://creativecommons.org/licenses/by/4.0/ (c) (i) Open Access

\begin{abstract}
This study designed to evaluate the entrance surface air kerma (ESAK) to the patient during X-ray examination to the skull antero-posterior (AP), skull Lateral (LAT), chest postero-anterior (PA), Lumber spine AP/LAT and Pelvis AP. Totally, 408 patients were included in this study using computed radiography (CR) in different three hospitals in Khartoum; five X-ray machines were covered. The entrance surface air kerma (ESAK) was calculated for each patient from the exposure parameters using different peak tube voltages. Patient's data such as (age and weight) and exposure parameters $(\mathrm{kVp})$ and $(\mathrm{mAs})$ were recorded. The result obtained showed that, the entrance surface air kerma ranged from 0.88 to $3.30 \mathrm{mGy}$ for Skull (AP), 0.588 to $1.87 \mathrm{mGy}$ for skull (LAT), 0.03 to $2 \mathrm{mGy}$ for chest PA, 1.50 to $3.40 \mathrm{mGy}$ Lumbar spine AP, 2.60 to $5.15 \mathrm{mGy}$ for Lumbar spine (LAT), and 1.05 to $4.40 \mathrm{mGy}$ for Pelvis. This study provides additional data that can help the regulatory authority to establish reference dose level for diagnostic radiology in Sudan. This study recommends that the CR operator must be used to optimize the patient dose by using the best strategies available for reducing radiation dose. Computed radiography must be used with high level training for medical staff to reduce the dose; each radiology department should implement a patient dose measurement quality assurance programme. Doses to the patients should be regularly monitored and the proposed national DRLs should be taken as guidance for optimization.
\end{abstract}

\section{Keywords}

ESAK, Estimation Dose, CR, Patient Dose, Effective Dose

\section{Introduction}

Present day computed radiography (CR) is based on the use of photostimulable phos- 
phors, which are also known as storage phosphors [1]. Computed radiography (CR) is at this moment the most common digital radiography modality in radiology departments, in place of conventional screen film systems. With the CR technology, the detector is a photostimulable phosphor screen, usually indicated as an imaging plate (IP).

They are commercially the most successful detectors for digital radiography; the phosphors used are most often in the barium fluorohalide family [2] in powder form and deposited onto a substrate to form an imaging plate or screen. X-ray absorption mechanisms are identical to those of conventional phosphor screens used with film. They differ in that the useful optical signal is not derived from the light emitted in prompt response to the incident radiation, but rather from subsequent emission when the latent image, consisting of trapped charge, is optically stimulated and released from metastable traps. This triggers a process called photostimulated luminescence (PSL) resulting in the emission of shorter wavelength (blue) light in an amount proportional to the original X-ray irradiation. In $\mathrm{CR}$, an imaging plate (IP) containing the storage phosphor is positioned in a light-tight enclosure, exposed to the X-ray image and then read out by raster scanning with a laser to release the PSL. The blue PSL light is collected with a light guide and detected with a photomultiplier tube (PMT). The PMT signal is digitized to form the image on a point-by-point basis [3].

The main advantages of CR include: wider dynamic range (latitude), ability for post processing (manipulation of radiographic contrast and brightness), multiple viewing options, electronic transfer and storage options [4]. The wide exposure latitude of CR means that a greater range of radiation exposures (mainly current-time product (mAs)) can be used to produce a diagnostic image [4].

Underexposure and overexposure with film-screen radiography (FSR) are associated with poor image quality and the film may need to be repeated; whereas underexposure in CR results in a grainy image (high noise) that could be tolerated with some post processing, and higher than appropriate exposures in CR leading to increasing image quality due to an increase in signal-noise ratio [5] [6] [7] [8]. Gross artefacts are not evident on CR until exposure levels are 100 times lower or 500 times greater than those used in FSR [8]. Thus, while there is a potential for reduced repeat examinations and hence dose reduction in $\mathrm{CR}$, it has been reported that radiographers develop a tendency to use higher than necessary exposure factors to improve image quality and avoid repeat radiographs. This tendency to increase exposure factors is referred to as exposure factor creep [6].

While FSR allows the radiographer to visually assess whether exposures are optimum, this direct visual assessment is lacking with CR systems. To allow for exposure parameter control and to safeguard from overexposure in CR, manufacturers have introduced numerical parameters that are a direct estimate of the incident exposure on the imaging plate [7]. Each manufacturer provides its own "exposure indicator", with an algorithm for its calculation; for example, this is called the exposure index (EI) by Kodak [8] and sensitivity (S) value by Fuji [9]. 


\section{Material and Method}

\subsection{X-Ray Unit}

This work was carried out in five public hospitals in Khartoum, Sudan and included five X-ray units. The hospitals are thereafter refereed as: A, B, C, D and E. These hospitals were chosen because they had a considerable number of $\mathrm{X}$-ray examination performed on daily basis.

\subsection{Parameters and Calculating of ESAK}

To calculate the ESAK, X-ray tube exposure parameters were recorded for each patient undergoing the specified diagnostic procedure: peak tube voltage $(\mathrm{kVp})$, exposure current-time product (mAs) and focus-to-film distance (FFD).

Radiographic projections studied were: Skull AP/PA and Skull LAT, Chest PA, Lumbar Spine AP, Lumbar Spine LAT and Pelvis AP. The ESAK (Ki) is defined as the air kerma to air on the X-ray beam axis at the point where the X-ray beam enters the patient or a phantom, including the contribution of the backscatter. The ESAK was calculated in the present work using the following relation [10] [11]:

$$
\mathrm{Ki}=\mathrm{Y}(d) \operatorname{Pi}\left(\frac{\mathrm{d}}{\mathrm{FSD}}\right)^{2}
$$

where $\mathrm{Y}(d)$ is the tube output per $\mathrm{mAs}$ measured at a distance of $100 \mathrm{~cm}$ from the tube focus along the beam axis at different $\mathrm{kVp}$ different $\mathrm{mAs}$ values typically encountered in the clinical practice. $\mathrm{Pi}$ is tube current exposure time product ( $\mathrm{mAs}) . \mathrm{kV}$ is peak tube voltage recorded for any given examination, $\mathrm{mAs}$ is the tube current-time product, FSD is the focus-to-surface distance is a backscatter factor for a particular examination at the required potential, taken from UK Health Protection Agency HPA (previously NRPB) numerical simulations [12].

\subsection{Patient Samples}

A total of 408 patients were examined in five hospitals in Khartoum state, patients undergone of one of the selected exams Skull, Chest, Lumber spine and Pelvis. The data were collected using a sheet for patients in order to maintain consistency of the information. The (collected data included) following parameters were recorded age, weight, height, Body Mass Index (BMI) derived from weight $(\mathrm{kg}) /(\text { height }(\mathrm{m}))^{2}$ and (tube voltage, and tube current-time product setting) exposure parameters were recorded. The dose was measured for four main examinations: Skull AP/PA and Skull LAT, Chest PA, Lumbar Spine AP, Lumbar Spine LAT and Pelvis AP. The examinations were collected according to the availability.

\section{Results and Discussion}

Doses were calculated in regard to 408 patients with Radiographic projections studied were: Skull AP/PA and Skull LAT, Chest PA, Lumbar Spine AP, Lumbar Spine LAT and Pelvis AP using measured tube output data and the patient specific exposure parameters. All X ray equipment for which doses were measured were properly maintained, 
checked as part of quality control program and were found to perform according to specification.

The data show the number of patients from five public hospitals in Khartoum, Sudan and included five X-ray units. The hospitals are thereafter refereed as: A, B, C, D and E. And the number of patients for each exam was 182,125,172 and 129 for skull, chest, lumber spine and pelvis examinations respectively.

For all examinations here the FFD for skull AP/PA and Skull LAT, Lumbar Spine AP, Lumbar Spine LAT and Pelvis AP was in range 100 to $120 \mathrm{~cm}$ and for Chest PA was 180 $\mathrm{cm}$.

The mean and $\pm S D$ values of all the patients examined to skull $\mathrm{X}$-ray were presented in Table 1. Study population Comprised 125 adult's patients (50\% for each male and female) patient age ranged from 28 - 70 years, Body Mass Index ranged from 18.54 to $26.67 \mathrm{~kg} \cdot \mathrm{m}^{2}$ with mean \pm SD $22.8 \pm 3.26 \mathrm{~kg} \cdot \mathrm{m}^{2}$, and ESAK ranged from 0.588 to 3.303 $\mathrm{mGy}$, with $1.704 \pm 0.682 \mathrm{mGy}$, and for Effective Dose $0.141 \pm 0.057 \mathrm{mSv}$ and ranged from 0.048 to $0.274 \mathrm{mSv}$.

The mean and \pm SD values of all the patients examined to chest X-ray were presented in Table 1. Study population Comprised 180 adult's patients $(52.6 \%$ for male and $47.4 \%$ female) patient age ranged from 16 - 88 years, Body Mass Index ranged from 19.02 to $27.123 \mathrm{~kg} \cdot \mathrm{m}^{2}$ with mean \pm SD $25.54 \pm 12.64 \mathrm{~kg} \cdot \mathrm{m}^{2}$, and ESAK ranged from 0.031 to $2 \mathrm{mGy}$ with the mean \pm SD $0.290 \pm 0.244 \mathrm{mGy}$, and for Effective Dose $0.023 \pm$ $0.018 \mathrm{mSv}$ and ranged from 0.002 to $0.0138 \mathrm{mSv}$.

The mean and $\pm S D$ values of all the patients examined to lumber spine $\mathrm{X}$-ray were presented in Table 1. Study population Comprised 172 adult's patients (64.8\% for male and 35.2\% female) patient age ranged from 21-88 years, Body Mass Index ranged from 19.03 to $26.53 \mathrm{~kg} \cdot \mathrm{m}^{2}$ with mean \pm SD $23.25 \pm 1.93 \mathrm{~kg} \cdot \mathrm{m}^{2}$, and ESAK ranged from 2.05 to $5.15 \mathrm{mGy}$ with the mean \pm SD $3.15 \pm 1.58 \mathrm{mGy}$, and for Effective Dose $0.127 \pm 0.067$ $\mathrm{mSv}$ and ranged from 0.087 to $0.365 \mathrm{mSv}$.

The mean and $\pm \mathrm{SD}$ values of all the patients examined to pelvis $\mathrm{X}$-ray were presented in Table 1. Study population Comprised 129 adult's patients $(58.7 \%$ for male and 41.3\% female) patient age ranged from 21 - 85 years, Body Mass Index ranged from 21.88 to $36.88 \mathrm{~kg} \cdot \mathrm{m}^{2}$ with mean $\pm \mathrm{SD} 24.13 \pm 4.34 \mathrm{~kg} \cdot \mathrm{m}^{2}$, and ESAK ranged from 1.05 to $4.402 \mathrm{mGy}$, with $1.53 \pm 0.814 \mathrm{mGy}$, and for Effective Dose $0.127 \pm 0.067 \mathrm{mSv}$ and ranged from 0.087 to $0.365 \mathrm{mSv}$.

Table 1. Patient demographic data and patient radiation doses during examinations of X-ray.

\begin{tabular}{|c|c|c|c|c|c|c|c|}
\hline Exam & $\begin{array}{l}\text { Age } \\
\text { Years }\end{array}$ & Gender & $B M I K g \cdot m^{2}$ & $\begin{array}{c}\text { Tube Voltage } \\
(K v)\end{array}$ & Tube Current (mAs) & $\begin{array}{l}E S A K \\
(m G y)\end{array}$ & $\begin{array}{c}\text { Effective Dose } \\
\quad(m S v)\end{array}$ \\
\hline \multirow{2}{*}{ Skull } & $48.89 \pm 11.05$ & Male $50 \%$ & $22.8 \pm 3.26$ & $69.64 \pm 5.18$ & $29.83 \pm 10.25$ & $1.704 \pm 0.68$ & $0.141 \pm 0.06$ \\
\hline & $28-70$ & Female $50 \%$ & $18.54-26.67$ & $62-78$ & $25-32$ & $0.588-3.303$ & $0.048-0.27$ \\
\hline Chest & $16-88$ & Female $47.4 \%$ & $19.02-27.12$ & $55-78$ & $8-18$ & $0.031-2$ & $0.002-.0138$ \\
\hline$L / S$ & $53.55 \pm 18.51$ & Male $64.8 \%$ & $23.25 \pm 1.93$ & $80.44 \pm 7.66$ & $27.66 \pm 11.87$ & $3.15 \pm 1.58$ & $0.261 \pm 0.089$ \\
\hline Pelvis & $21-85$ & Female $41.3 \%$ & $21.88-36.88$ & $60-88$ & $12-45$ & $1.05-4.402$ & $0.087-0.365$ \\
\hline
\end{tabular}


Table 2 shows statistical parameters in four for ESAK mean, median, STD, minimum, maximum and third quartile for all patients with different X-ray examinations according to gender, gender and statistical parameters including mean, median, STD, minimum, maximum and third quartile for ESAKs.

Table 3 shows statistical descriptive of ESAK mGy depending on the exam projection, statistical parameters Mean, Median, standard deviation, minimum, maximum and third quartile of ESAK mGy was used to Skull AP/PA and Skull LAT, Chest PA, Lumbar Spine AP, Lumbar Spine LAT and Pelvis AP.

Compared between present study with international study and international organization, the ESAK found in this study was lower than that reported by International organizations. However, the results compared with some establishing international dose reference dose levels such as IAEA, CEC in Table 4.

Table 2. Standard deviation for ESAK in mGy according to gender.

\begin{tabular}{|c|c|c|c|c|c|c|c|}
\hline Exam & Gender & Mean & Median & STD & Min & $\operatorname{Max}$ & Quartile $^{3 \mathrm{~d}}$ \\
\hline \multirow{2}{*}{ Skull } & Male & 1.79 & 1.79 & 0.66 & 0.78 & 3.30 & 2.17 \\
\hline & Female & 1.61 & 1.55 & 0.71 & 0.59 & 2.97 & 1.90 \\
\hline Chest & Female & 0.26 & 0.18 & 0.17 & 0.03 & 0.80 & 0.35 \\
\hline $\mathrm{L} / \mathrm{S}$ & Male & 3.83 & 3.14 & 1.92 & 0.25 & 5.15 & 5.23 \\
\hline \multirow{2}{*}{ Pelvis } & Male & 1.52 & 1.40 & 0.83 & 1.05 & 4.40 & 1.88 \\
\hline & Female & 1.55 & 1.65 & 0.80 & 0.94 & 3.49 & 2.12 \\
\hline
\end{tabular}

Table 3. Show descriptive statistic of ESAKD ( $\mathrm{mGy}$ ) in all hospitals according to exam projection.

\begin{tabular}{|c|c|c|c|c|c|c|}
\hline Exam/Projection & Mean & Median & $S T D$ & Min & $\operatorname{Max}$ & ${ }^{3 d}$ Quartile \\
\hline Skull $A P / P A$ & 2.11 & 2.01 & 0.66 & 0.88 & 3.30 & 2.66 \\
\hline Skull LAT & 1.29 & 1.45 & 0.42 & 0.59 & 1.9 & 1.66 \\
\hline$L / S A P$ & 2.72 & 2.722 & 1.41 & 1.50 & 3.40 & 3.80 \\
\hline$L / S L A T$ & 4.01 & 3.503 & 1.68 & 2.60 & 5.15 & 5.50 \\
\hline
\end{tabular}

Table 4. Compression of this study with international studies and IDRLs [13] [14] [15] [16] [17].

\begin{tabular}{|c|c|c|c|c|c|c|}
\hline \multicolumn{4}{|c|}{ Internationals study [13] [14] } & \multicolumn{3}{|c|}{ International DRLs [15] [16] [17] } \\
\hline Exam & Present & Australia 2011 & Italy 2005 & IAEA 2004 & CEC & NRPB \\
\hline Skull AP/PA & 2.11 & 3 & 1.91 & 5 & 5 & 3 \\
\hline Chest PA & 0.29 & 0.2 & 0.25 & 0.4 & 0.3 & 0.2 \\
\hline L/S AP & 2.72 & 6 & 2.98 & 7 & 10 & 6 \\
\hline Pelvis AP & 1.53 & 4 & - & 10 & 10 & 4 \\
\hline
\end{tabular}

List of Symbols and Acronyms: ESAK: Entrance Surface Air Kerma; CEC: Commission of the European Communities; IAEA: International Atomic Energy Agency; NRPB: National Radiological Protection Board; BMI: Body Mass Index. 
However, the risk from radiation exposure of the patients must be balanced versus the diagnostic benefit. Many departments do not use recommended radiographic parameters for patient using digital radiography, furthermore, wide variations in the applications of the radiographic techniques, equipment performance at different hospitals over the world.

\section{Conclusions}

The patient dose was measured in five large hospitals for different computed radiography modalities. The findings from the present study showed that optimization of technical and clinical factors may lead to a substantial patient dose reduction.

The results of this study allow a better understanding of how different working habits and examination technology influence the patient doses and make medical staff aware of their responsibility for optimization of daily radiological practice.

For all the examinations studied in the hospital, the mean ESAK values obtained are found to be within the standard reference values of doses.

Reference dose levels for diagnostic radiology must be established on the national scale, in order to reduce the patient exposure and to maintain a good diagnostic image.

\section{References}

[1] Sanada, S., Doi, K., Xu, X.-W., Yin, F.-F., Giger, M.L. and MacMahon, H. (1991) Comparison of Imaging Properties of a Computed Radiography System and Screen-Film Systems. Medical Physics, 18, 414-420. http://dx.doi.org/10.1118/1.596688

[2] Barnes, G.T. (1993) Digital X-Ray Image Capture with Image Intensifier and Storage Phosphor Plates: Imaging Principles, Performance and Limitations Digital Imaging (AAPM Monograph No. 22). Hendee, W.R. and Trueblood, J.H., Eds., Medical Physics, Madison, 23-48.

[3] Fujita, H., Ueda, K., Morishita, J., Fujikawa, T., Ohtsuka, A. and Sai, T. (1989) Basic Imaging Properties of a Computed Radiographic System with Photostimulable Phosphors. Medical Physics, 16, 52-59. http://dx.doi.org/10.1118/1.596402

[4] International Commission on Radiological Protection (2003) Managing Patient Dose in Digital Radiology. Elsevier: ICRP Publication, 93.

[5] Lu, Z., Nickoloff, E., So, J. and Dutta, A. (2002) Comparison of Computed Radiography and Film Screen Combination Using a Contrast Detail Phantom. Journal of Applied Clinical Medical Physics, 1, 91-96.

[6] Willis, C. (2002) Computed Radiography: A Higher Dose? Pediatric Radiology, 32, 745-850. Seibert, A. (2004) Computed Radiography Technology. Department of Radiology, University of California Davis Medical Center Sacramento, California.

[7] Peters, S. and Brennan, P. (2002) Digital Radiography: Are the Manufacturers' Settings Too High? Optimisation of the Kodak Digital Radiography System with Aid of the Computed Radiography Dose Index. European Radiology, 12, 2381-2387.

http://dx.doi.org/10.1007/s00330-001-1230-0

[8] Kodak (2001) Guidelines for Acceptance Testing and Quality Control. Kodak Directview CR 800 System and Kodak Directview CR 900 System.

[9] Nakajima, N., Takeo, H., Ishida, M. and Nagata, T. (1995) Fuji Computed Radiography: Technical Review No.3. In: Automatic Setting Functions for Image Density and Range in 
the FCR System, Fuji Photo Film Co., Japan.

[10] International Commission on Radiation Measurements and Units (2006) Patient Dosimetry for X-Rays Used in Medical Imaging. ICRU Report No. 74, ICRU, Bethesda, MD.

[11] International Atomic Energy Agency (2007) Dosimetry in Diagnostic Radiology: An International Code of Practice. IAEA TRS. No 457, IAEA, Vienna.

[12] Kramer, K.., Khoury, H.J. and Vieira, J.W. (2008) CALDose X-A Software Tool for the Assessment of Organ and Tissue Absorbed Doses, Effective Dose and Cancer Risks in diagnostic Radiology. Physics in Medicine and Biology, 53, 6437-6459. http://dx.doi.org/10.1088/0031-9155/53/22/011

[13] Australian Radiation Protection \& Nuclear Safety Agency (2008) ARPANSA RPS 14.1 Safety Guide for Radiation Protection in Diagnostic and Interventional Radiology. Australian Radiation Protection \& Nuclear Safety Agency, Yallambie.

[14] IAEA, International Atomic Energy Agency (2004) International Basic Safety Standard for Protection against Ionizing Radiation and for the Safety of Radiation Sources. Safety Series No 115. IAEA, Vienna, Austria.

[15] Compagnone, G., Pagan, L. and Bergamini, C. (2005) Local Diagnostic Reference Levels in Standard X-Ray Examinations. Radiation Protection Dosimetry, 133, 54-63.

[16] Johnston, D.A. and Brannan, P.C. (2000) Reference Dose Levels for Patients Undergoing Common Diagnostic X-Ray Examinations in Irish Hospitals. BJR, 73, 396-402. http://dx.doi.org/10.1259/bjr.73.868.10844865

[17] International Atomic Energy Agency (1996) International Basic Safety Standards for Protection against Ionising Radiation and for the Safety of Radiation Sources. IAEA Safety Series No. 115, IAEA, Vienna.

\section{Submit or recommend next manuscript to SCIRP and we will provide best service} for you:

Accepting pre-submission inquiries through Email, Facebook, LinkedIn, Twitter, etc.

A wide selection of journals (inclusive of 9 subjects, more than 200 journals)

Providing 24-hour high-quality service

User-friendly online submission system

Fair and swift peer-review system

Efficient typesetting and proofreading procedure

Display of the result of downloads and visits, as well as the number of cited articles

Maximum dissemination of your research work

Submit your manuscript at: http://papersubmission.scirp.org/

Or contact ijmpcero@scirp.org 